UDC 37.06

LBC 74.04

\title{
THE INCREASING ROLE OF EDUCATIONAL TOURISM IN THE TRAINING SYSTEM OF THE WORLD TOURIST INDUSTRY: A SOCIO-PHILOSOPHICAL INQUIRY ${ }^{1}$
}

\author{
Vasiliy V. Gerneshiy \\ Peoples' Friendship University of Russia, Moscow, Russian Federation
}

\begin{abstract}
The article presents the theoretical generalization of educational tourism as a social phenomenon of modern society. It is shown that educational tourism is now an integral part of the international systems of higher education for training in tourism. Educational tourism is seen as a particular social institution included in the life of the modern state and aimed at continuous modernization and stratification. The specificity of educational tourism, consisting of the synergistic unity of education and tourism, pedagogical principles, and forms of organization of tourist activity, is deduced. Methodologically, the work is done based on a comparative analysis of the training system for the tourism industry in the Russian Federation with relevant educational institutions of some European countries (in particular, Great Britain, France, Germany, Switzerland). The author reveals the specifics and characteristics of Russian and European educational systems, considering modern societies' economic, technological, and cultural features for training professional staff for the tourism industry. It is emphasized that European educational institutions have significant historical experience in training specialists for the tourism industry. In this regard, proposals for the use of positive foreign experience in training specialists for the tourism industry in the educational activities of Russian universities are outlined. External and internal conditions and factors influencing the educational systems of tourism and hospitality training have been revealed. Particular attention is paid to the requirements imposed on such systems by the professional community. The article reveals the goals, objectives, and forms of implementation of educational tourism in European and Russian systems of training for tourism and hospitality. The most crucial goal of educational tourism at the state level, according to the author, is the formation of a multilateral personality, capable of active and constructive activities in a multi-ethnic and multi-religious environment, with the ability to live in peace and harmony with people of different ethnic cultures and religions.
\end{abstract}

Key words: social institution of tourism, educational tourism, competence model of education, migration factors of tourism, Russian and European educational models, globalization.

Citation. Gerneshiy V.V. The Increasing Role of Educational Tourism in the Training System of the World Tourist Industry: A Socio-Philosophical Inquiry. Logos et Praxis, 2021, vol. 20, no. 3, pp. 166-176. (in Russian). DOI: https://doi.org/10.15688/lp.jvolsu.2021.3.16

УДК 37.06

ББК 74.04

\section{ВОЗРАСТАНИЕ РОЛИ ОБРАЗОВАТЕЛЬНОГО ТУРИЗМА В СИСТЕМЕ ПОДГОТОВКИ КАДРОВ МИРОВОЙ ТУРИНДУСТРИИ: СОЦИАЛЬНО-ФИЛОСОФСКИЙ АНАЛИЗ ${ }^{1}$}

\author{
Василий Васильевич Гернеший \\ Российский университет дружбы народов, г. Москва, Российская Федерация
}

Аннотация. В статье представлены результаты теоретического обобщения исследований образовательного туризма как социального феномена современного общества. Показано, что образовательный туризм является сегодня неотъемлемой составной частью международных систем высшего образования по подго- 
товке кадров для сферы туризма. Образовательный туризм рассматривается как особый социальный институт, включенный в жизнедеятельность современного государства и нацеленный на постоянную модернизацию и стратификацию. Выявлена специфика образовательного туризма, заключающаяся в синергийном единстве образования и туризма, педагогических принципов и форм организации туристской деятельности. Методологически работа выполнена на основе компаративного анализа системы подготовки кадров для туриндустрии в Российской Федерации с соответствующими образовательными институтами некоторых европейских стран (в частности, Великобритании, Франции, Германии, Швейцарии). Автор раскрывает специфику и характерные черты российских и европейских образовательных систем, учитывающих экономические, технологические и культурные особенности современных обществ для подготовки профессиональных кадров для сферы туриндустрии. Подчеркивается, что европейские образовательные учреждения имеют значительный исторический опыт в этой сфере. В связи с этим изложены предложения по использованию положительного зарубежного опыта подготовки специалистов для туриндустрии в образовательной деятельности российских университетов. Выявлены внешние и внутренние условия и факторы, влияющие на образовательные системы подготовки кадров для области туризма и гостеприимства. Особое внимание уделено требованиям, предъявляемым к таким системам профессиональным сообществом. В статье раскрываются цели, задачи и формы реализации образовательного туризма в европейских и российской системах подготовки кадров для сферы туризма и гостеприимства. Важнейшей целью образовательного туризма на государственном уровне, по мнению автора, является формирование многосторонней личности, способной к активной и конструктивной деятельности в многоэтничной и полирелигиозной среде, обладающего умением жить в мире и согласии с людьми различных этнокультур и вероисповеданий.

Ключевые слова: социальный институт туризма, образовательный туризм, компетентностная модель образования, миграционные факторы туризма, российская и европейская образовательные модели, глобализация.

Цитирование. Гернеший В. В. Возрастание роли образовательного туризма в системе подготовки кадров мировой туриндустрии: социально-философский анализ // Logos et Praxis. - 2021 . - Т. 20, № 3. - C. 166-176. DOI: https://doi.org/10.15688/lp.jvolsu.2021.3.16

\section{Образовательный туризм как фактор формирования качественного потенциала мировой туриндустрии}

Одной из отличительных характеристик начала XXI столетия явилось глобальное распространение туризма. Динамичное развитие и рост мирового туризма позволили промышленно развитым и развивающимся странам приобрести ощутимые экономические выгоды, увеличить рост занятости во многих смежных секторах - от строительства до сельского хозяйства и телекоммуникаций. За период 2010-2019 гг. объем доходов от оказанных туристских услуг приблизился к объемам экспорта нефти, продуктов питания или автомобилей (а иногда и превосходил их). Туризм стал одним из основных игроков в международной торговле и источников дохода для многих развивающихся стран.

Несмотря на определенный спад, вызванный пандемией коронавируса COVID-19 в 2020 г., в среднесрочной перспективе специалисты Всемирной туристской организации (UNWTO) уверенно прогнозируют дальнейший устойчивый рост международного туризма. Такая тенденция характеризуется не только большим потенциалом для развития мировой экономики, но и обусловливает появление ряда проблем, связанных с человеческим потенциалом.

Возможности заключаются в увеличении доли инвестирования и создании качественных рабочих мест в мировой туриндустрии. Особенно это важно для развивающихся стран. Проблема же состоит в том, что для поддержки ожидаемого роста, а также для достижения конкурентоспособности и устойчивости туристического сектора потребуется адекватная база человеческого капитала в сфере туризма. При планировании развития человеческого капитала в сфере туризма важно также учитывать, что сегодняшние потребности туриндустрии в таком капитале не совпадают с соответствующими потребностями в 2030 г. и в более отдаленной перспективе. Через 5-7 лет мы увидим появление новых видов туристического бизнеса, продуктов, услуг и профессий, требующих различных компетенций, знаний и личностных качеств.

Высокая потребность в специализированном человеческом капитале для удовлет- 
ворения условий национальных туристических агентств и частных компаний является одной из основных проблем, с которыми сталкиваются туристические направления в настоящее время. Кадровый потенциал мировой туриндустрии главным образом формируется качественным образованием. Однако с определенной долей уверенности можно утверждать, что не все национальные туристские образовательные школы способны готовить специалистов туриндустрии, соответствующих потребностям сегодняшнего и завтрашнего дня.

В настоящее время выпускники туристских вузов в своей профессиональной деятельности оказываются в условиях, когда они должны уверенно владеть востребованными и актуальными компетенциями не только на национальном уровне, но и на уровне мировой туриндустрии. Свобода выбора и многообразие потребностей человека обусловили появление в мировом образовательном пространстве весьма широкого спектра образовательных услуг. Среди них и образовательный туризм, ставший в короткие сроки динамично развивающимся сектором экономики с растущей глобальной популярностью и признанием. Существует множество определений этого понятия. Мы будем опираться на определение Всемирной туристской организации (UNWTO) - «поездки с целью "образование и профессиональная подготовка"», связанные с такими основными видами деятельности, как «посещение краткосрочных курсов, прохождение определенных программ обучения (формальных или неформальных) или приобретение определенных навыков с помощью формальных курсов» [Пономарева 2015, 12].

В статье рассматривается только основной вид образовательного туризма, цель которого - получение профессионального образования, в конечном счете стимулирующего интеллектуальную миграцию молодежи. Разновидности образовательного туризма, в которых путешествие направлено на познание отдельных объектов или характеристик этнической культуры того или иного народа (например, экскурсии по культурно-историческим достопримечательностям, мастер-классы по народным промыслам и т. д.), являются лишь дополнением к основной программе туристского маршрута и в данной статье не рассматриваются.
Говоря о туризме, в том числе образовательном, следует учитывать, что его феномен содержательно гораздо шире общепринятого понимания путешествия, так как он обладает собственной бытийной сущностью, ценностным наполнением, знаковой природой, коммуникативным и когнитивным потенциалом. Он фокусирует в себе наиболее существенные изменения и тенденции развития современного общества, такие как мобильность, акцентирование потребительских приоритетов, виртуализация, визуализация, информатизация, глобализация [Чистякова 2010, 7].

Рассматривая характерные черты образовательного туризма, следует отметить прежде всего его интегративную природу, которая проявляется в результате объединения и взаимопроникновения образовательной и туристской деятельности. Можно утверждать, что по своей функциональной сути образовательный туризм является особой формой организации образовательной деятельности, осуществляемой вне границ образовательного учреждения. Разумеется, что в основе привлекательности такого вида туризма лежит не путешествие в традиционном его понимании, не новые впечатления, а содержательные и востребованные образовательные программы профессионального уровня.

При этом следует учитывать, что образовательный туризм рассматривается как высокоэффективная технология обучения и одновременно форма обеспечения учебного процесса. Грамотное проектирование этого вида деятельности выявляет туристско-ресурсный потенциал и степень аттрактивности территорий в целях развития образовательного туризма. В этом контексте последний можно рассматривать как фактор международной интеллектуальной миграции молодежи и лиц, решивших получить дополнительное специальное образование.

Очевидно, что образовательный туризм в современном обществе представляет собой особый социальный феномен, связывающий в единство образование и туризм для получения профессионального образования в сфере индустрии туризма и гостеприимства. Социально-философский анализ проблемы становления образовательного туризма в современном мировом пространстве позволяет гово- 
рить о том, что процессы глобализации способствовали усложнению структур общественного бытия, но вместе с тем способствовали и формированию качественно новой социальной стратегии познания и освоения новых территорий при посредстве образовательного туризма. Учитывая современные реалии технологически развитых обществ, следует отметить, что этот вид туризма уже приобрел значимость важнейшего элемента подготовки кадрового потенциала, адекватного требованиям современной туриндустрии.

\section{Основные формы и задачи современного образовательного туризма}

Исходя из того, что образовательный туризм является динамично развивающимся сектором туриндустрии, имеющим признание во всем мире, многие исследователи относят его к числу лидирующих и перспективных суботраслей туризма. По оценкам специалистов Бизнес-школы Сколково, рост количества студентов, участвующих в образовательном туризме, в мире выглядит впечатляющим и к 2025 г. достигнет 8 млн человек. Такая тенденция прослеживается и в российских вузах. В 2019 г. количество иностранных студентов в российских вузах превысило 240 тыс. чел., а к 2025 г. по прогнозам этот показатель достигнет 710 тыс. чел. [Сероштан, Кетова 2020, 14].

Динамика мирового образовательного туризма вполне сопоставима с динамикой ведущих отраслей экономики. Привлечение иностранных студентов - значимый фактор международной деятельности российских университетов, их социальной ответственности и экономической устойчивости. Очевидно, что это один из главных путей интеграции отечественных университетов в мировое образовательное пространство. Доходы от экспорта российского образования достигают до 95 млрд руб. в год [Сероштан, Кетова 2020, 8]. Немаловажным является и то, что часть иностранных выпускников трудоустраиваются в нашей стране, а мы получаем квалифицированные кадры для отраслей экономики.

Принадлежа к институту образования, этот вид туризма представляет собой определенную форму организации учебного процесса со своими специфическими целями и задача- ми. Фундаментальная цель образовательного туризма состоит в формировании человека, способного к активной и конструктивной деятельности в многоэтничной и полирелигиозной среде, обладающего развитым чувством понимания и уважения других культур, умением жить в мире и согласии с людьми разных национальностей и вероисповеданий.

Указанная цель определяет важнейшие задачи, реализация которых способствует ее достижению и подтверждает предположение, что образовательный туризм является сегодня самодостаточной суботраслью индустрии туризма, нацеленным на решение ряда задач:

- формирование у студентов понимания качества образовательной мобильности, которое нацеливает на поиск образовательных ресурсов, соответствующих современным социальным запросам;

- повышение культурной грамотности, которая является первичной для подготовки кадров для сферы туризма и обеспечивает компетенцию получать образование в разных культурных средах. Культура в этих условиях становится основой социального действия и коммуникативной компетентности;

- формирование умений и навыков самообразования. Изыскания, которые обучающиеся должны предпринимать во время реализации программы образовательного туризма, - это, по существу, индивидуальные образовательные траектории, во многом самостоятельные исследования [Гришаева 2016, 35].

Образовательный туризм в определенной степени решает и задачу сглаживания социального неравенства. В условиях неравномерности социального и экономического развития регионов зачастую возникает невозможность для значительной части молодежи знакомиться с историческими достопримечательностями других городов, с туристскими дестинациями, относящимися к различным этнокультурам и религиям. В реализации образовательного вида туризма эта проблема частично решается посредством целевого получения образования и одновременного познавательного освоения нового пространства. При этом образовательный туризм оказывает намного более эмоциональное воздействие на учебный процесс, особенно на освоение новых знаний, чем традиционные педагогичес- 
кие методы. Прежде всего, это связано с непосредственностью восприятия исторического места или культурного события.

Исходя из сказанного, очевидно, что рассматриваемый тип туризма может стать не только качественным инструментом профессионального образования, но и эффективным фактором воспитания. В этом и состоит его главная цель. В этом контексте российский исследователь образовательного туризма С.Ю. Житинев отмечает, что развитие и становление образовательного туризма на современном этапе адекватно общемировым тенденциям развития образования, а потому он может стать важным элементом дополнения действующих образовательных программ и практик, существенным стимулом совершенствования индивидуального обучения и усвоения знаний учащимися [Житинев 2018, 6].

Как интегративный продукт, включающий собственно туристскую составляющую и учебный компонент в контексте туристской инфраструктуры, образовательный туризм находит свою имплементацию посредством многообразных синтетических форм. Сюда относятся учебные поездки с целью изучения общеобразовательных или специальных предметов, обучающие языковые туры, практические поездки в учреждения, организации и на предприятия для повышения квалификации, научные и учебные стажировки в научных учреждениях и образовательных организациях, получение академического образования со степенью, участие в семинарах и конференциях.

Конечно, в различных странах существует свой потенциал для развития образовательного туризма. Обратимся к европейским традициям, имеющим богатый опыт подготовки специалистов для туриндустрии.

\section{Особенности \\ европейских образовательных систем подготовки кадров для туриндустрии}

Все вышеперечисленные аспекты наложили свой отпечаток на мировые образовательные системы подготовки кадров для туриндустрии, обусловили наличие общих черт, но при этом позволили сохранить различия национальных образовательных систем. Ряд зарубежных стран, таких как Великобритания, Франция, Германия, Швейцария накопили значительный опыт профессиональной подготовки персонала для сферы туризма.

Рейтинг конкурентоспособности стран в области туризма (ТTCI), ежегодно рассчитываемый экспертами Всемирного экономического форума, показывает, что страны-лидеры в области подготовки отраслевых кадров занимают также высокие позиции по совокупным показателям конкурентоспособности.

Франция, как известно, относится к странам активного туристского въезда (насчитывается более 85 млн туристских прибытий ежегодно). Проведя краткий анализ французской образовательной системы подготовки, приходим к следующим выводам:

- профессиональное образование в сфере туризма представлено на уровнях второй, третьей ступенях и послевузовского образования;

- на уровне второй ступени функционируют профессиональные училища и центры профессиональной подготовки со сроками обучения 2-3 года;

- реализуются в основном практикоориентированные образовательные программы с присвоением квалификации по диплому двух видов: САР - диплом о присвоении квалификации по профессии; ВЕР - диплом об общей профессиональной подготовке.

На следующем уровне второй ступени работают техникумы и технологические институты со сроками обучения 2 года. Выпускникам выдается диплом о присвоении квалификации. Иногда эту ступень называют «короткий цикл высшего образования»; в туризме - BTS (4-й квалификационный уровень профессии: гид, организатор путешествий, консультант по путешествиям).

На уровне высшего образования существуют 2 ступени лицензиата - аналог бакалавриата и магистратуры. В лицензиате обучение длится 3 года. На эту ступень обучения может поступить лицо, имеющее диплом бакалавра, полученного в результате успешной пройденной итоговой аттестации по результатам обучения на длинном (лицейском) цикле старшей школы.

Бакалавры выпускаются с гуманитарной, естественно-научной и экономической профилизацией. Отдельная траектория уровня ли- 
цея позволяет сдать экзамен на диплом STT, подтверждающий освоение компетенций в сфере обслуживания. Магистерские программы также предлагают варианты: 60 3Е - одногодичные магистерские программы (без профилизации) и 120 3Е - двухгодичные магистерские программы (с профилизацией); широко представлены программы «делового администрирования» (МВА).

На разных уровнях профессионального образования в сфере туризма Франции присутствует вариативность: длинный или короткий цикл обучения, профилизация, различные траектории освоения компетенций [Organisation de l'école... web]. Особенность французской модели подготовки кадров для туриндустрии заключается в развитой системе межинституциональных связей, обеспеченной в нормативно-правовом плане, и регламентации содержания образовательной деятельности в сфере туризма.

Отличительной особенностью модели управления туризмом в Великобритании является ее определенная автономия. Задачи развития туризма и проектирование туристской деятельности возложены на независимые от государства туристские организации и бизнессообщества (Local Enterprise Partnerships). Система профессионального образования в сфере туризма Великобритании базируется на профессиональных стандартах (National Occupational Standards), определяющих содержание образовательных программ в сфере туризма [The Travel \& Tourism... web]. В Великобритании создана централизованная система имплементации квалификационно-профессиональной структуры в содержании профессионального образования. Образовательные программы разрабатываются на основе Рамки квалификаций и кредитов (Qualifications and Credit Framework). Квалификации состоят из разделов, представляющих собой содержание ключевых компетенций, выраженных в кредитах. Занимая уверенные конкурентные позиции в сфере туризма в мире, Великобритания имеет высокие показатели занятости в туриндустрии и существенный опыт подготовки кадров для туризма. Британская система отличается жесткой привязкой к национальным профессионально-квалификационным стандартам, в которых каждый квалификационный уровень вы- ражен в конкретной академической и практической нагрузке, требуемой для его освоения.

Британская модель образования в сфере туризма нацелена на удовлетворение актуальных потребностей в компетентностных характеристиках работников туризма. Одной из отличительных черт британской модели является ее ориентация на индивидуальный выбор обучающегося. Механизмы профессиональной ориентации, по сути, являются в британской модели саморегулируемыми, не управляемыми со стороны государства. Однако, следует подчеркнуть, что в британской системе в меньшей степени выражены гуманизирующие начала, такие как ранняя профориентация, нацеленность на индивидуальное развитие в течение всей жизни, чем, например, это наблюдается в австрийской или норвежской моделях.

Положителен опыт Швейцарии в подготовке кадров для туриндустрии. Особенностью швейцарского образования является его активный экспорт в другие страны. Экспорт швейцарских образовательных услуг, в первую очередь в отельном менеджменте, свидетельствует об их высоком качестве. Фактически за рубеж вывозятся образовательные технологии, а жизнеспособность последних за границей подтверждает доверие потребителей к швейцарским образовательным программам. Это является свидетельством их высокого уровня и конкурентоспособности. По статистике национального швейцарского офиса, в Швейцарских высших учебных заведениях $30 \%$ студентов составляют иностранные студенты. Швейцарское образование в сфере туризма является востребованным в рамках академических уровней бакалавриата, магистратуры, а также специалитета.

Состояние структуры и содержания образования в сфере туризма Швейцарии позволяет утверждать, что обучение персонала средних квалификационных уровней обеспечивается на основе исключительно практикоориентированного подхода. Особое внимание государства к системе подготовки кадров для туризма Швейцарии уделяется среднему сегменту (3-4-й квалификационные уровни), что представляется вполне обоснованным. Статистика занятости в туризме европейских стран показывает, что именно в 
этом сегменте занято наибольшее число сотрудников. Швейцарская система подготовки кадров для туризма обладает высокой степенью интегрированности и институциональной прочности, основываясь на взаимодействии профессиональной области, профильных государственных структур и образовательных учреждений.

Проведенный краткий компаративный анализ европейских образовательных систем подготовки кадров для туриндустрии показывает, что, несмотря на их национальные различия, все они имеют один общий признак практикоориентированность. Предприятия туризма достаточно широко интегрированы в процесс образовательной деятельности. При этом передача опыта, технологий обучения систематизируется и регламентируется на национальном уровне так же, как и процесс квалификации по результатам профессионального обучения.

\section{Возможные направления} совершенствования качества

и привлекательности

\section{туристского образования в России}

Несмотря на то что туристское образование в системе подготовки кадров для нашей страны достаточно новое направление, ему присущи все современные тенденции развития высшего образования в России: конкурентоспособность, инновационность, эффективность, свобода выбора формы получения образования, гуманизация [Артамонова 2010, 14]. В последние годы в Российской Федерации в туристском и гостиничном бизнесе произошли существенные качественные изменения, усовершенствовались технологии, выросла степень информатизации, компьютеризации и пр. Все это обусловлено качественными и динамичными изменениями в турбизнесе России. Разумеется, что в таких условиях подготовка кадров для туриндустрии не может не носить инновационный и опережающий характер.

В настоящее время в образовательных организациях высшего образования подготовка кадров для туристской отрасли ведется по установленным Министерством науки и высшего образования РФ трем направлениям под- готовки укрупненной группы специальностей (УГСН 43.00.00) «Сервис и туризм»- Сервис, Туризм, Гостиничное дело по уровням бакалавриат и магистратура. Следует отметить, что в основу подготовки положена компетентностная модель подготовки специалиста туриндустрии, тесно привязанная к профессиональным стандартам области предстоящей профессиональной деятельности.

Несмотря на определенную регламентацию деятельности при реализации образовательных программ указанных выше направлений подготовки федеральными образовательными стандартами высшего образования, университеты и институты имеют право самостоятельно устанавливать профиль (направленность) программы. Такой подход существенно диверсифицирует количество и качество образовательных программ, позволяет адекватно реагировать на требования регионального туристского бизнеса, своевременно адаптировать программы к изменяющимся условиям отечественной и мировой экономики. Положительным в туристском образовании РФ является то, что структурно-логическая схема освоения образовательных программ построена с учетом принципов междисциплинарности и мультидисциплинарности. Ведущие университеты страны уже успешно реализуют принцип трансдисциплинарности [Пирогова 2016, 9].

Туристское образование в России достигло определенных успехов за относительно короткое время. Однако ему предстоят еще серьезные изменения, обусловленные новыми трендами в мировом образовании, влияющими на подготовку кадров в сфере туризма. Это глобализация образования, кластеризация вузов, бизнеса и профессиональных сообществ, геймификация в образовании, гиперконкуренция, быстрое развитие отраслей и др. В мировой экономике наблюдается устойчивая тенденция постепенной трансформации труда. Всем очевиден мировой тренд неоднократной смены профессии одним человеком за период трудовой деятельности.

Технологии в современном туризме меняются слишком быстро и, как следствие, устаревают и профессиональные знания. Часть полученных умений и навыков в университете может устареть до его окончания. 
Ежегодно в мире «умирает» более 500 профессий, возникает более 600 новых, при этом динамика только нарастает [Пирогова 2016, 12].

В связи с вышеперечисленными тенденциями возникают требования к формированию новых компетенций. По существу, система подготовки специалистов для туриндустрии сталкивается с новыми вызовами, которые потребуют новых решений в реализации образовательных программ и нестандартных подходов (методов) подготовки кадров. В связи с этим в современных условиях одним из ключевых факторов конкурентоспособности становится человеческий капитал и его высокое качество.

Современные процессы трансформации общества все более активно будут использовать новые образовательные технологии. В этих условиях университеты столкнутся с необходимостью разрабатывать новые образовательные программы и грамотно управлять новыми образовательными траекториями. Потребуется оперативно реагировать на изменения в туристской отрасли и своевременно вносить адекватные требованиям времени и туристской бизнесиндустрии изменения в структуру и содержание подготовки кадров. Процессы глобализации уже предопределили процесс интеграции вузов туриндустрии России в международную образовательную среду.

В Стратегии развития туризма в Российской Федерации на период до 2035 г. определено, что достижение высокого уровня оказываемых услуг, сервиса и обслуживания клиентов требует комплексного подхода, в первую очередь в части создания условий обеспечения отрасли достаточным количеством квалифицированных кадров [Распоряжение Правительства РФ от 20.09.2019 № 2129-р... web]. Кроме того, для повышения эффективности функционирования отрасли в целом за счет обеспечения качества сервиса оказываемых услуг, формируемых туристских продуктов, а также гостеприимства на уровне лучших мировых практик необходимы настройка механизмов удовлетворения будущих потребностей в кадрах, долгосрочное планирование и построение системы подготовки кадров всех уровней.

С учетом сложившегося международного опыта профессионального образования пер- сонала для индустрии туризма и гостеприимства, прежде всего в странах - лидерах туристской индустрии, требований Стратегии развития туризма года мы можем полагать, что концепция профессионального туристского образования, предполагающая непрерывность, цикличность, поэтапность обучения и многоуровневость, повышение квалификации, профессиональную переподготовку, подтвердила свою жизнеспособность в изменяющихся условиях и может быть приемлема в качестве ориентира при совершенствовании систем подготовки кадров. Однако с учетом складывающихся тенденций в развитии национальных образовательных систем ведущих стран мира этого уже недостаточно.

Для сохранения и поддержания статуса ведущей образовательной системы подготовки кадров для туриндустрии в международной образовательной среде, обеспечения и удержания конкурентных преимуществ в мировом туристском образовании российской высшей школе, на наш взгляд, целесообразно опираться на ряд принципов в развитии туристского образования. Выделим некоторые из них:

- создание современных условий для обучения, соответствующих постоянно изменяющейся производственной среде в индустрии туризма и гостеприимства и росту конкуренции;

- углубление специализации профессиональной подготовки в условиях производственной гибкости, позволяющей специалисту быстро адаптироваться при любых изменениях производственной среды и требующей профилирования обучения, учебно-методических материалов, преподавательских кадров;

- интернационализация системы туристского образования, связанная с переходом индустрии туризма и гостеприимства от национального к многонациональному характеpy [Chistyakov 2019, 2188], повышением уровня требовательности потребителей к качеству и ассортименту туристского продукта, ростом стандартов и требований к туристскому персоналу;

- развитие системы дополнительного образования, повышения квалификации и профессиональной переподготовки кадров, в том числе на основе новых форм образования, дистанционного образования [Распо- 
ряжение Правительства РФ от 20.09.2019 № 2129-p... web].

- интеграция систем туристского образования с производством в туризме и гостеприимстве в действующую учебно-производственную систему.

Опираясь на передовой международный опыт подготовки кадров туризма и исходя из прикладного характера, гибкости и динамично меняющейся сферы туриндустрии в отечественных образовательных системах, следует поддержать тот факт, что туристская деятельность требует инновационных и нетрадиционных подходов в обучении. Одним из таких подходов может быть реализация рекомендаций Министра науки и высшего образования РФ В. Фалькова о предоставлении студентам возможности выбирать за пределами вуза $25 \%$ курсов и возложении на вуз обязанности обеспечить реализацию такого выбора. Возможно даже встраивать курсы лучших мировых университетов в российские образовательные программы или делать их комплементарными. Такой подход может стать отчасти революционным в качестве высшего образования и позволит сделать его еще более привлекательным и конкурентноспособным.

Следующее направление повышения престижа и привлекательности отечественного туристского образования - открытие туристскими вузами значительного количества онлайн-курсов. Это обусловлено тем обстоятельством, что по оценкам Международной ассоциации университетов (IAU) только $2 \%$ студентов могут воспользоваться возможностью обучения за рубежом [Салми 2019, 45]. С ростом качества программ электронного перевода, а этот процесс в эпоху цифровизации неизбежен, студенты получат доступ к образовательным ресурсам на любом языке. В этих условиях наличие качественных онлайн-курсов может снизить количество непосредственно прибывающих в нашу страну иностранных студентов, но вместе с тем существенно увеличить число студентов, осваивающих наши образовательные программы в режиме онлайн-курсов.

Сегодня в педагогическом сообществе существует много споров о преимуществах и недостатках онлайн-курсов. Но уже неоднократно мы получали убедительные доказатель- ства, что таким путем материал действительно усваивается на порядок лучше по сравнению с обычной лекцией. Передовые университеты, как правило, группируют онлайн-курсы по 15-20-минутным модулям в целях непревышения психологического порога усталости от усвоения.

Сама специфика туризма предопределяет широкое международное сотрудничество и в этой связи важным может быть совместная реализация образовательных программ с наиболее известными туристскими зарубежными вузами, привлечение к преподаванию отдельных курсов ведущих профессоров этих университетов. Российский университет дружбы народов уже достаточно длительное время практикует такой подход, показавший свою высокую эффективность. Студенты более 157 стран обучаются в РУДН на разных направлениях подготовки, в том числе и по туризму. Все они имеют возможность за период обучения прослушать курсы профессоров зарубежных вузов, изучать образовательные программы, реализуемые университетом совместно с зарубежными партнерами, обучаться определенное время в зарубежном вузе-партнере.

Наш опыт работы показал и все возрастающую значимость летних (зимних) школ как одного из важных видов образовательного туризма. Программы этих школ сохраняют популярность среди студенческой молодежи и демонстрируют устойчивую динамику. Даже в условиях пандемии, когда работа школ проводилась в дистанционном режиме, количество реализованных программ и доля слушателей практически не изменились по отношению к обычному формату.

Такая образовательная практика показала, что количество принимаемых в университет студентов (как отечественных, так и зарубежных) ежегодно возрастает, а сам РУДН стал весьма авторитетным, узнаваемым и привлекательным университетом в международном образовательном пространстве, что, в свою очередь, не преминуло отразиться на существенном росте его позиций в международных рейтингах университетов.

Важным представляется и международная аккредитация образовательных туристских программ, что наряду с профессиональ- 
но-общественной аккредитацией придает этим программам высокую привлекательность, конкурентноспособность в международном образовательном пространстве. Они делают полученное образование в университете «брендовым». Именно эти программы привлекают молодые умы и таланты со всего мира. В связи с этим существенной является и позиция, занимаемая университетом в глобальных рейтингах. Чем выше позиции в ключевых рейтингах, тем выше и доверие к университету, а соответственно, и востребованность его программ.

Российское туристское образование обладает значительным потенциалом, опирается на опыт и прочную репутацию отечественной высшей школы. Оно вполне способно решить задачу обеспечения высокого уровня его конкурентноспособности в мировом образовательном пространстве, востребованности выпускников профессиональным сообществом и обеспечения российской туриндустрии высокопрофессиональным кадровым потенциалом. Активная трансформация ведущих университетов нашей страны привела к переосмыслению своих образовательных моделей, в основе которых лежала очная коммуникация преподавателя и студента, позволила обновить старую и создать новую инфраструктуру, наработать новые компетенции. Такое положение в определенной степени предопределило снижение падения спроса на образование, позволило минимизировать дополнительные риски для университетов. Сохранение высокого уровня конкуретноспособности и привлекательности образовательных программ российских университетов послужит основой для дальнейшего развития образовательного туризма в нашей стране.

\section{ПРИМЕЧАНИЕ}

${ }^{1}$ Исследование выполнено при финансовой поддержке РФФИ в рамках научного проекта № 20-011-00045 А «Влияние этнокультурных, религиозных, коммуникативных, образовательных и миграционных факторов на развитие современной индустрии туризма: опыт социально-философского анализа».

The reported study was funded by RFBR, project number 20-011-00045 A "The Influence of
Ethnocultural, Religious, Communicative, Educational and Migration Factors on the Development of the Contemporary Tourism Industry: Socio-Philosophical Inquiry."

\section{СПИСОК ЛИТЕРАТУРЫ}

Артамонова 2010 - Артамонова Е.И. Академическая мобильность как средство интеграции российских вузов в мировую систему высшего образования // Педагогическое образование и наука. 2010. № 1. С. 10-20.

Гришаева 2016 - Гришаева С.А. Миграционный потенциал иностранных студентов // Актуальные проблемы управления. 2016. № 3. С. 15-21.

Житинев 2018 - Житинев С.Ю. Образовательный туризм в России М.: Юрайт, 2018.

Пирогова 2016 - Пирогова О.В. Перспективы развития туристского образования // Современные проблемы науки и образования. 2016. № 6. C. 10-19.

Пономарева 2015 - Пономарева Т.В. Образовательный туризм: сущность, цели и основные сегменты потребителей // Проблемы современной экономики. 2015. № 2. С.11-23.

Распоряжение Правительства РФ от 20.09.2019 № 2129-p... web - Распоряжение Правительства РФ от 20.09.2019 № 2129-р «О Стратегии развития туризма в РФ на период до 2035 г. // Собрание законодательства РФ. 2019. №27. Ст. 3314 .

Салми 2019 - Салми Д. Обеспеченность равного доступа к высшему образованию в разных странах // Международное высшее образование. 2019. № 98. С. 43-49.

Сероштан, Кетова 2020 - Сероштан М.B., Кетова Н.П. Современные Российские университеты: позиционирование, тренды, возможности наращивания конкурентных преимуществ // Высшее образование в России. 2020. № 2. C. 12-33.

Чистякова 2010 - Чистякова О.В. Проблемы этнокультурной политики в «национализирующемся» государстве // Вестник Российского университета дружбы народов. 2010. № 4. C. 5-12.

Chistyakov 2019 - Chistyakov D. Media Praxis in Constructing Symbolic Space: Intercultural Approach // Proceedings of the $4^{\text {th }}$ International Conference on Contemporary Education, Social Sciences and Humanities. Series: Advances in Social Science, Education and Humanities Research. 2019. P. 2176-2179.

Organisation de l'école... web-Organisation de l'école. Ministère de l'Éducation nationale, de la Jeunesse 
et des Sports // https://www.education.gouv.fr/ organisation-de-1-ecole-12311.

The Travel \& Tourism... web - The Travel \& Tourism Competitiveness Report 2017. The World Economic Forum // https://www.weforum.org/ reports/the-travel-tourism-competitivenessreport-2017.

\section{REFERENCES}

Artamonova E.I., 2010. Academic Mobility As a Means of Integrating Russian Universities into the Global System of Higher Education. Pedagogicheskoe obrazovanie i nauka, no. 1, pp. 10-20.

Grishaeva S.A., 2016. Migration Potential of Foreign Students. Aktual'nye problemy upravlenija, no. 3, pp. 15-21.

Zhitinev S.Y., 2018. Educational Tourism in Russia. Moscow, Jurajt Publ.

Pirogova O.V., 2016. Prospects for the Development of Tourism Education. Sovremennye problemy nauki i obrazovanija, no. 6, pp. 10-19.

Ponomareva T.V., 2015. Educational Tourism: Essence, Objectives, and Main Segments of Consumers. Problemy sovremennoj jekonomiki, no. 2, pp. 11-23.

Decree of the Government of the Russian Federation from 20.09. 2019 № 2129-r "On the Strategy of
Tourism Development in the Russian Federation for the Period up to 2035". Sobranie zakonodatel'stva $R F$, no. 27, art. 3314.

Salmi D., 2019. Ensuring Equal Access to Higher Education in Different Countries. Mezhdunarodnoe vysshee obrazovanie, no. 98, pp. 43-49.

Seroshtan M.V., Ketova N.P., 2020. Modern Russian Universities: Positioning, Trends, Possibilities to Increase Competitive Advantages. Vysshee obrazovanie v Rossii, no. 2, pp. 12-33.

Chistyakova O.V., 2010. Problems of Ethno-Cultural Policy in the "Nationalizing" State. Vestnik Rossijskogo universiteta druzhby narodov, no. 4, pp. 5-12.

Chistyakov D., 2019. Media Praxis in Constructing Symbolic Space: Intercultural Approach. Proceedings of the $4^{\text {th }}$ International Conference on Contemporary Education, Social Sciences and Humanities. Series: Advances in Social Science, Education and Humanities Research, pp. 2176-2179.

Organisation de l'école. Ministère de l'Éducation nationale, de la Jeunesse et des Sports. URL: https://www.education.gouv.fr/organisation-de1-ecole-12311.

The Travel \& Tourism Competitiveness Report 2017. The World Economic Forum. URL: https:// www.weforum.org/reports/the-travel-tourismcompetitiveness-report-2017.

\section{Information About the Author}

Vasiliy V. Gerneshiy, Candidate of Military Sciences, Associate Professor, Director of the Hotel Business and Tourism Institute, Peoples' Friendship University of Russia, Miklukho-Maklaya St, 6, 117198 Moscow, Russian Federation, v.gerneshij@yandex.ru, https://orcid.org/0000-0003-3288-814X

\section{Информация об авторе}

Василий Васильевич Гернеший, кандидат военных наук, доцент, директор института гостиничного бизнеса и туризма, Российский университет дружбы народов, ул. Миклухо-Маклая, 6 , 117198 г. Москва, Российская Федерация, v.gerneshij@yandex.ru, https://orcid.org/0000-0003-3288-814X 